\title{
Evaluating engineering thinking in undergraduate engineering and liberal arts students
}

\author{
Sarah Bell ${ }^{a *}$, Andrew Chilvers ${ }^{\mathrm{b}}$, Liz Jones $^{\mathrm{c}}$ and Nicole Badstuber ${ }^{\mathrm{d}}$ \\ ${ }^{a}$ Institute for Environmental Design and Engineering, UCL, 14 Upper Woburn Place, \\ London WC1H ONN, +44 (0)20 3108 6925, s.bell@ucl.ac.uk; ${ }^{b}$ Royal Academy of \\ Engineering, 3 Carlton House Terrace, London SW1Y 5DG, +44 (0)20 77660600 , \\ Andrew.Chilvers@raeng.org.uk; ${ }^{c}$ Civil, Environmental and Geomatic Engineering, \\ UCL, Gower St, London WC1E 6BT, +44(0)20 7679 0674, liz.jones@ucl.ac.uk; ${ }^{d}$ Civil, \\ Environmental and Geomatic Engineering, UCL, Gower St, London WC1E 6BT, \\ +44(0)20 7679 7224, n.badstuber@ucl.ac.uk. \\ *corresponding author
}

Sarah Bell is Professor of Environmental Engineering and Director of The Engineering Exchange at UCL. She is a Chartered Engineer and Fellow of the Chartered Institute of Water and Environmental Management. Her research interests include sustainable urban water systems and community engagement with infrastructure and engineering. She is an EPSRC Living With Environmental Change Research Fellow, researching bottom-up approaches to urban infrastructure provision.

Andrew Chilvers is Senior Policy Advisor to the Royal Academy of Engineering and an Honorary Lecturer at the UCL Department of Science, Technology, Engineering and Public Policy. His doctoral research developed ethnographic studies of engineers-inpractice that critically explored how engineers understand and engage with the appropriation of values in and through their practices, and how and why certain values are integrated into outcomes (or not), particularly in relation to social and environmental sustainability. His work focuses on research and capacity building for better socio- 
technical integration across engineering institutions. This includes in engineering education, design and engineering consultancy and in engineering advice to government.

Liz Jones is Director of Studies in the UCL Department of Civil, Environmental and Geomatic Engineering. She joined the CEGE department after working as a surveyor in the 3D team of Plowman Craven. Prior to this, she completed a BA in Egyptian Archaeology (UCL), MA in Egyptology (Liverpool) and an MSc in GIS (UCL). Liz holds the positions of Principal Teaching Fellow and Geomatic Systems Manager, and provides consultancy both in a technical and educational capacity. She is a Fellow of the Higher Education Academy.

Nicole Badstuber is a researcher in Urban Transport Policy and Governance at UCL. She is a doctoral student in the Department of Civil, Environmental and Geomatic Engineering. Her research focusses on transport policy and governance for city regions. 


\section{Abstract}

This paper presents a new approach to teaching and evaluating professional skills ('engineering thinking' competencies) in first year undergraduate liberal arts (BASc) students, and comparison with first year civil and environmental engineering undergraduates, within problem- and project-based learning (PBL) environments. This study explored if it is possible for liberal arts students to develop engineering professional competencies without detailed engagement with the engineering sciences. A new method for evaluating such competencies was developed. Two one-hour individual problem-solving exercises were devised to assess capabilities against 14 criteria, based on the Institution of Civil Engineers' Competency framework for professional development (2011). At the beginning and end of the academic term students in both cohorts completed one of these exercises and a self-evaluation exercise. Anonymised and randomised outputs were assessed by two evaluators. The BASc cohort's scores for each criterion improved notably from the start of term to the end. This cohort rated their capabilities more highly at the end of term and was more satisfied with the answers they gave. Engineering students showed a slight decline in performance against the criteria. Self-evaluation in this group revealed a smaller increase in perceived capability but increased dissatisfaction. Both cohorts felt more anxious about the assignment at the end of term. PBL environments can improve student competence in attributes associated with professional engineering. The scope of the study is constrained by the small cohort but the findings and evaluation method provide the basis for further development, including detailed statistical evaluation and validation of the evaluation instrument.

Keywords: word; evaluation methods, engineering competence, professional skills, interdisciplinary, problem-based learning

\section{Introduction}

Reform and innovation in engineering education are often motivated by the need to better prepare students for engineering practice in highly complex environments. Problem-, project- and scenario-based learning have been at the heart of many programmes which aim to improve student learning of engineering principles and skills. Engineering educators are faced with the challenge of ensuring graduates have a sound knowledge of 
their core discipline, are competent in engineering methods of analysis and design, and are able to work with other professionals in order to deliver outcomes that meet client needs and have positive impacts for society and the environment. For many graduates, engineering education is also the foundation for careers outside of the engineering profession. Engineering education must be seen as providing grounding in a unique and powerful system of knowledge, which can be applied in many different professional contexts.

It is common, and often required, for engineering undergraduates to take courses in mathematics or the natural or social sciences as part of their core engineering studies. It is less common for students in other disciplines to include engineering courses within their programmes. Engineering courses often require highly specialised, usually mathematical, prerequisites, which exclude students from non-engineering programmes. Whilst engineering graduates may benefit from the experience of learning within other knowledge traditions, engineering itself is often inaccessible to a wider community of scholars. Reform of engineering education, which focusses on engineering methods and transferrable skills as distinct from technical education in specific engineering sciences, provides opportunities to open up engineering education to a wider range of students. The pedagogical challenge of teaching engineering to non-engineering students also presents an opportunity to develop and test new methods of teaching that aim to achieve learning outcomes beyond the core engineering science. Evaluating the effectiveness of new approaches to teaching engineering methods and skills is a further challenge, requiring the development of new instruments for measurement and evaluation. 
In 2012 University College London instigated a new liberal arts undergraduate programme, the Bachelor of Arts and Sciences (BASc). This is unique in the United Kingdom where undergraduate degrees are specialised and students have limited opportunities for interdisciplinary learning. Engineering Thinking is a first year option available to all students on the BASc. The module provides an introduction to engineering as a profession and practice, emphasising engineering as a distinct system of knowledge of particular importance to modern society. The learning outcomes for the module are:

- Use engineering analysis to design an appropriate solution to a problem.

- Integrate engineering standards, practical know-how and scientific knowledge in implementing an engineering project.

- Describe the role of engineering in modern society.

The Engineering Thinking module was evaluated using an instrument developed specifically to assess changes in students' abilities in core engineering competences as defined by the Institution of Civil Engineers. The Engineering Thinking cohort was compared to a cohort of students enrolled in undergraduate programmes in Civil and Environmental Engineering.

This paper describes the content and approach of the Engineering Thinking module and the Civil and Environmental Engineering programme which was used as a comparison cohort. These courses are discussed in the context of reforms to engineering education focusing on problem-based learning. The evaluation method is described as a means of assessing the effectiveness of problem-based learning in achieving core 
engineering professional competencies. The results of the evaluation of the Engineering Thinking module are discussed in comparison with the Civil and Environmental Engineering cohort. The paper concludes with a discussion of the effectiveness of the Engineering Thinking approach to teaching engineering method and skills, and the usefulness of the evaluation instrument in assessing changes in student capabilities in core engineering competences.

\section{Engineering Thinking at UCL}

The Engineering Thinking module at UCL in 2012 was centred on a project, which was presented as an engineering contract between students, acting as consultants and contractors, and the university estates management department, acting as the client. Students were given a 'call for tenders' document at the beginning of term for a project relating to water metering on the university campus. Teams of students bid for the project in the middle of the course, and then the winning team's proposal was implemented by the whole class working together. The project followed the systems engineering lifecycle, starting with defining user requirements, moving through detailed engineering design and ending with the installation and testing of the final system. The system was finally handed over to the client, including documentation of the installation and analysis of preliminary data. The system as installed, including errors and incomplete components, then became the basis for further development by students in subsequent cohorts, progressively building a network of sensors and a database of water consumption data in one university toilet block. The students also participated in lectures and seminars which addressed different aspects of engineering, including ethics, data analysis and an introduction to the science of fluid mechanics. 
The unique position of Engineering Thinking within a liberal arts programme required the teaching team to reflect upon the general principles of engineering which transcend disciplines such as civil, electrical and mechanical engineering. The module and the project were designed to emphasise transferrable engineering skills and knowledge, and to characterise engineering as a distinct and powerful way of thinking.

Problem-based learning is increasingly accepted as best practice in engineering education. Students are usually presented with realistic problems but their solutions are rarely implemented, limiting their learning to engineering as a theoretical construct. Learning how to implement solutions is an important, though often overlooked, part of learning to be an engineer. For this reason, the module was designed to be based upon a project to deliver a working technical system to a client.

In order to evaluate the effectiveness of the module in developing engineering competencies the Engineering Thinking cohort was compared to a similar cohort of first year students in civil and environmental engineering. The Department of Civil, Environmental and Geomatic Engineering (CEGE) at UCL pioneered scenario-based teaching of engineering in the UK (Bell et al. 2010). In 2006 the department implemented a major curriculum reform, centred on week-long scenarios, in which students work in groups to solve a specific, complex problem. The scenarios occurred four times each year, with more traditional lectures and laboratory classes in the preceding four weeks. The curriculum reforms also introduced greater emphasis on contextual factors influencing civil and environmental engineering practice such as engineering ethics, sustainable development and economics, and transferrable skills such as communication and project management. 


\section{Teaching and measuring engineering thinking}

The two cohorts used in this research project experience problem-based learning in hybrid project- and scenario- forms. These approaches are widely recognised as promoting development of high-order skills and deep approaches to learning, and are increasingly accepted as best practice in engineering education. They are a direct result of curriculum redesign in light of strong calls for change from government, professional bodies and industry to ensure that graduate engineers have greater experience of addressing 'real' engineering problems and are subsequently equipped with a broad set of professional skills alongside their specialist technical knowledge (Mills and Treagust 2003; Graham and Crawley 2010). When investigating if the United States Accreditation Board of Engineering Technology (ABET) professional skills could be taught and assessed, Shuman et al. (2005) concluded that such skills could indeed be taught but not necessarily within the traditional lecture format. The provision of meaningful engineering contexts (projects, scenarios etc.) in such curricula improves active learning and develops critical thinking and professional competencies in student engineers; skills highly-desired by industry (Fernandes et al. 2012). Engagement with engineering project tasks fosters skills in the application and processes of approaches to engineering problem-solving rather than in simply the acquisition of technical knowledge (Mills and Treagust 2003). It is these high-order skills which we define here as 'Engineering Thinking'.

Methods for developing these competencies in students generally lie within problem-based learning scholarship and to some extent its overlap with scholarship on how to embed professional skills into engineering programmes. At University College 
Dublin, Gavin (2011) developed a problem-based module with a joint structural and geotechnical case study to teach design skills to Civil Engineering students. Palmer and Hall (2011) embedded problem-based learning into the Design and Professional Skills module at Griffith University, Australia, in the form of group work on three design projects, including a civil design project to design and construct a geometric scale model of an urban development site. At the University of Minho, Portugal, Fernandes et al. (2012) used project work and a mini-conference to foster the development of general professional competencies for cohorts in Informatics Engineering. Most case studies involve a degree of group work but Denayer et al. (2003) developed a guided self-study project where students were given an open-ended problem, its context and useful documentation and asked to describe how they would approach finding a solution. The emphasis here was more on processes and not the technical knowledge required to solve the problem, and they found that with no unique solutions, the problems elicited creative responses from their cohort.

Whilst there is a wealth of studies on the benefits of adopting a more problemfocused approach to curriculum design in engineering and, to some extent, its implementation in specific modules and across broader curricula, there is a lack of comprehensive and rigorous outcomes assessment strategies and a paucity of literature on how such methods can be evaluated in a meaningful framework (Graham and Crawley 2010). Articles that do address evaluation tend to focus on student satisfaction and student perceptions or incorporate measurement of engineering thinking into formal assessment models with the purpose of returning grades and feedback to students. Consideration of how the efficacy of these techniques can be measured in relation to 
student capabilities in engineering thinking, and evaluations of the impact of learning, are rare.

Bell et al. (2010) used a modified Course Evaluation Questionnaire (CEQ), administered to students of the previous and new programmes in Civil and Environmental Engineering at UCL over a three-year period, to evaluate students' experiences and perceptions of the new scenario-centred degree programmes. Fernandes et al. (2012) also used a questionnaire to assess student perceptions of attainment of professional competencies, measured in relation to whether proposed goals were achieved and asking students to rate aspects of their course. Gavin (2011) implemented student feedback questionnaires at the end of his Civil Engineering design module, to understand students' experiences and perceptions of the hybrid problem-based learning environment, but not to evaluate the impact of learning on the cohort's engineering competence. Other methods where evaluation is in the hands of the participants, and examples of baselined activities include the work of Segalàs et al. (2008) using conceptual maps (Cmaps). In this case, students were asked to describe their knowledge by means of specific terms and in terms of connections between them, to stimulate the students to articulate and externalise the state of their knowledge. Cmaps were used because they have been shown to be very useful in assessing students' prior knowledge. Palmer and Hall (2011) surveyed students on their project-based Design and Professional Skills module at the start and end of the course to gauge students' changing perspectives of the course.

Approaches where evaluation is not undertaken by the participants themselves but by external experts (e.g. tutors) remove the potential weaknesses of self-perception. 
Burrow et al. (2005) designed an exercise to address the cognitive elements associated with engineering thinking, as a formative assessment for their cohort; using the RECAP taxonomy (Recall, Comprehension, Application and Problem Solving), devised by Imrie (1995) as a modification of the Bloom's taxonomy, to aid question design and to ensure that higher levels of learning were addressed in their evaluation. To remove the human subjective element of assessment, Blake and Gutierrez (2011) evaluated student competence by analysis of free-form text Management Achievement Program (MAP) responses. Jaeger and Adair (2014) used a portfolio assignment to assess achievement of learning outcomes in two project-based learning engineering design courses.

The problem-solving exercise as measurement tool is particularly suitable and appealing as a method for evaluating engineering thinking because problem-, projectand scenario-based curricula are more likely to develop the high-order skills we would associate with 'engineering thinking'. At the University of California Berkeley, McMartin et al. (2000) designed a problem-solving assignment for students on a mechanical engineering programme. Each student was given a 'day in the life of an engineer' problem and asked to outline the processes they would follow to try to solve the problem; set as a two-hour individual homework assignment. The analytic rubric developed to assess students' knowledge was designed to evaluate how the students would approach finding a solution to the problem rather than their abilities to solve the particular technical or design problem. It is this competency in identifying, describing and applying processes and approaches that lies at the core of Engineering Thinking, which is the focus of this study. 
In terms of criteria-definition, if problem-based learning more closely mirrors professional behaviour than other pedagogies, educators should take advantage of the professional frameworks available to them for the purposes of outcomes evaluation (Mills and Treagust 2003). However, whilst professional accreditation bodies may provide outcomes-based criteria, there is variation in how each programme can interpret them (Brumm et al. 2006). Having identified a need for an instrument that evaluates student competence and the impact of their learning experiences on their development as holistic engineers, in relation to the frameworks of the accreditation bodies, Male et al. (2010) classified 64 competencies required for engineering students, drawn from a broad literature base. Briedis (2002) developed a method for assessment of student professional outcomes for both grading and evaluation purposes, using an 'outcomes vision’ approach based on United States Accreditation Board of Engineering Technology (ABET) designated criteria.

\section{Methods}

By defining 'engineering thinking' as high-order professional skills and understanding that such skills are best developed in problem-, project-based and hybrid learning environments, our methodology for measuring and evaluating 'engineering thinking' comprises a problem-solving exercise and criteria taken from the Institution of Civil Engineers' Competency Framework, with a short questionnaire to understand students' perceptions of their capabilities.

The study seeks to determine the impact that the new module, Engineering Thinking, had on student's engineering competencies and skill sets. To achieve this, it sought to measure the performance of two undergraduate cohorts - the Bachelor of 
Engineering in Civil Engineering (CEGE) students and Bachelor of Arts and Sciences (BASc) students - in individually taken problem-solving exercises set at the beginning and the end of the teaching term. Exercise outputs were assessed against competencies taken from the Competency framework for professional development devised by the Institution of Civil Engineers (2011). The results reported here are the first application of this instrument to evaluate the impact of engineering education on professional competence.

The evaluation took place over the first term of the first year of both courses, with student competence assessed at the beginning and end of the term. All 8 of the BASc students taking Engineering Thinking participated in the evaluation, and 14 CEGE students formed the comparison cohort. At the beginning of the term the students had no prior experience of their current course of study, and most had no prior university experience. Students on both programmes had similarly high requirements for university entrance, with engineering students on average having stronger prior knowledge of maths and science. The BASc students were enrolled in a number of other modules which were not engineering related, and their end of term results on the evaluation task may reflect wider learning as well as their experience of the Engineering Thinking module. Core modules in the first year of the BASc include 'Approaches to Knowledge', 'Interdisciplinary Research Methods', 'Quantitative Methods and Mathematical Thinking' and a non-English language.

The students were set two different problem-solving exercises with both cohorts divided up into two equal groups at the beginning of the term. The evaluation was based on assessment of a one-hour individual problem-solving exercise against an adapted 
competency framework. One half of each cohort worked on one problem-solving exercise (Exercise A), the other on a second exercise (Exercise B). Students were also asked to self-assess how well they felt prepared for the task, how anxious they felt about the task and their satisfaction with their response to the task, and to explain their assessment of these factors. The method was repeated with both cohorts at the end of the term, but with each group switching the problem-solving exercise: those who worked on Exercise A at the start of term worked on Exercise B at the end of the term and vice versa. This way half of each cohort worked on the same problem-solving exercise at the same points in the year, but no student completed the same exercise twice. Students also completed the same self-assessment task as at the beginning of term, to measure any changes in anxiety and satisfaction with their completion of the task. The written responses to the problem-solving tasks were assessed by two independent evaluators, and a third evaluation was done in cases of significant difference between the scoring. The student responses were anonymised and randomised to avoid cohort or other bias in the evaluations.

\section{Problem-Solving Exercises}

The problem-solving exercises were adapted from material used in engineering outreach activities, providing confidence that they were achievable for students without prior experience of engineering. In Exercise A students were asked to address the problem of heating and ventilation for a multi-purpose building at their university which also has significant heritage status. In Exercise B are asked to address the problem of sustainable energy provision to a remote community. Scaled down versions of the problem-solving exercises for the students participating in this study are provided in the following sections. 
These problem-solving exercises were devised with two main sets of considerations in mind: 1) best-practice principles in problem-based learning and evaluation; and 2) practical feasibility for students and staff. In terms of the former, open ended problems and question-framings were devised so that students had interpretative freedom in determining how the overall problems should be tackled and what considerations they took as salient. Secondly, and given the open-ended, interpretative nature of the questions posed, significant attempts were made to provide a realistic and believable context for the problems posed. Finally, the exercise materials were devised with the competencies which we sought to elicit and evaluate in mind in that attention was given as to whether there was scope in each problem-solving exercise to demonstrate the competencies being evaluated (elaborated in the next section).

From a pragmatic point of view, design of this evaluation had to take account of the existing learning and assessment demands on students and manage the additional demand from the evaluation activity. Given that a key part of this study is the comparison of the BASc cohort with a cohort of engineering students - two fundamentally different courses - the exercises completed by the two cohorts had to be comparable and thus this evaluation exercise could not be integrated into the course materials. Thus, a key consideration had to be keeping the demands of this evaluation activity down to a reasonable additional load for participating students. The exercises were limited in their scope so that they could be feasibly completed in a one hour, examination-style session. These practical limitations had knock-on impacts on the scope of competencies it was reasonable to evaluate for, as discussed below. 


\section{Exercise A: The Chadwick Building}

The Chadwick Building is one of UCL's main buildings and houses the Department of Civil, Environmental and Geomatic Engineering (CEGE). However, this particular building presents some unique challenges as a building under ongoing use by UCL. Firstly, it is listed because of its historical and architectural features and it is extremely important that it is looked after and these features are preserved. However, the building was built during Victorian times (in 1894) and is now 118 years old and also in that time it has housed a great many activities and academic departments. This has led to a range of problems.

Ventilation is one of these. The building has a large diversity of inlets and outlets. The bad overall ventilation and the unplanned approach has meant that various different air conditioning units and extra fans have been installed in different rooms throughout the building as ad hoc corrective measures.

The temperature of the building is also difficult to control. Parts of the building overheat in both summer and winter, whilst others are uncomfortably cool in winter. It is not uncommon for staff in some offices to have an individual air conditioning unit running during winter, to relieve overheating.

You are a project engineer within the firm 'Building Solutions' and you have been approached by CEGE to devise a new system for improving thermal comfort in the building. This will include heating and ventilation. Your system must improve the comfort of building users whilst decreasing energy usage. Any viable solution must accommodate the fact that the Chadwick Building must continue to host a diverse range of users and activities. 
As an engineer, how would you approach and solve this task? Please include in your answer the considerations you are taking into account.

[The materials for the exercise also included a detailed description of building lay out, main features (with pictures and floor plans) as well as the range of uses and activities undertaken within.]

\section{Exercise B: Community Energy Supply}

People in the remote parts of the UK have raised concerns about the high price they pay for goods and services. This problem has increased significantly with the economic recession and has been investigated and reported on by the Office of Fair Trading. Remote communities typically suffer from the following:

- Inaccessibility of some goods, services or infrastructure typically found elsewhere;

- Weak market competition, and;

- Extra charges on delivery of goods and services.

Overall, this often results in much higher prices for goods and services when compared to elsewhere.

Community $\mathrm{X}$ is an example of a small community to whom these problems apply. Community $\mathrm{X}$ is the only community situated on Island $\mathrm{X}$; one of the smaller islands of the Outer Hebrides (a group of islands off the West coast of Scotland. The community consists of approximately 200 people (roughly 60 households) and is predominantly a 
fishing village ... which reduces the community's reliance on imported food. It is situated on the coast, at the outlet of a river whilst overlooked by mountains - through which various tributaries to the main river flow - the community is surrounded by an open, wind-swept landscape.

Such is the remoteness of Community $\mathrm{X}$ that it is not connected to mains supplies of either gas or electricity. Thus, the 200 or so villagers currently use diesel generators ... to supply their daily energy needs. However, the rising cost of diesel, of transporting fuel to the village, and the costs of maintenance works on their increasingly old generators is becoming a real economic burden.

The people of Community $\mathrm{X}$ have commissioned you as project engineer within the engineering firm, 'Energy Solutions' to solve this problem. They have commissioned your services to evaluate and deliver new solutions for the supply of energy to ensure that their village remains a viable community into the future.

As lead project engineer, how would you solve this problem? Please include in your answer the considerations you are taking into account.

[Students were also provided with maps and photographs of the island] 


\section{Evaluation}

The Institution of Civil Engineers (ICE) accredits university and college courses and degrees in engineering on the basis of the course fostering engineering knowledge and skills. Completing such a course can be the first step to becoming a chartered engineer in the UK. The ICE's (2011) Competency framework for professional development systematically identifies key attributes for engineers. It is an assessment tool used to highlight engineers' training and development needs in order to become well-rounded engineering professionals. In this way, the framework pinpoints the knowledge, skills, attitudes and behaviours the ICE values in engineering training and in its members.

The ICE differentiates between two streams of competencies: Foundation Competencies and Professional Competencies. The former are knowledge-based and would be expected to be developed within a formally accredited civil engineering undergraduate degree, such as those offered in the Department of Civil, Environmental and Geomatic Engineering at UCL. Professional competencies are split into three categories;

- Practice competencies: 'The behaviours, skills, knowledge and attitudes required for the effective application of theory, development of engineering solutions and specialisation' (ICE, 2011, p. 40).

- Behavioural competencies: 'The behaviours, skills, knowledge and attitudes required for the establishment and maintenance of effective working relationships' (ICE, 2011, p. 40).

- Contextual competencies: 'The behaviours, skills, knowledge and attitudes required for awareness and interaction with the environment, including external 
considerations in a business, cultural, political and economical context' (ICE, 2011, p. 40).

Professional Competencies relate to personal attributes 'used in work activities which underpin competent performance' and, the ICE expects would be gained through 'experience and interaction' and it is these that are covered in their Competency framework for professional development (ICE, 2011, p. 2). As such, the competencies listed in the framework are not required as part of the professional accreditation of engineering degree courses but are rather part of the comprehensive set of attributes which should be factored into an engineer's continuous professional development. As such, the framework is not intended to be seen as a standard or benchmark but rather outlines the competencies that combine to encompass the range of attributes required to become a well-rounded practitioner in long-term professional development (ICE, 2011).

In total there are 29 competencies listed in the Institution of Civil Engineer's framework with thirteen of these falling in the behavioural competencies category, ten into practice competencies and six in the contextual competencies area. It was this breadth of attributes covered by this framework - outside of formal knowledge-based requirements - which underpinned our choice of this framework of competencies as a starting point for thinking about our own course evaluation framework for capturing 'Engineering Thinking', broadly defined above. As an assessment using the framework does not require a minimum engineering knowledge level it was suitable to use to compare the performance of undergraduate engineering students and students studying a liberal arts undergraduate programme. 
Whilst this framework of 29 competencies was chosen as a starting point for the range of competencies that could possibly be considered in our evaluation. For practical reasons, it was necessary to narrow down this range. The scope of the exercise completed by the students was limited within the one hour available for the evaluation task. Evaluators could not feasibly accommodate a marking short responses according to all 29 competencies. Finally, some of the competencies listed in the framework clearly require a level of maturity and professional experience outside of the undergraduate competency levels that could reasonably be expected.

A lean version of the ICE's framework was devised for assessment of student performance in the tasks set as part of this study, Table 1 sets these out with ' $\mathrm{P}$ ', ' $\mathrm{B}$ ' and ' $\mathrm{C}$ ' denoting the Practice, Behavioural and Contextual competencies respectively and where the high-level competency listed above the sub-competencies that were taken forward into the study. A rating of student performance - between 1 and 5 - was made against each of the above competencies based on the students' output transcripts from the problem-solving exercises set. The rating between 1 and 5 corresponded to the ICE's definition of a competency range, given in 


\section{Table 2.}

[Tables 1 and 2 here]

\section{Results}

The small numbers in the study mean that full statistical analysis of the results is not meaningful. Results are presented as averages for each cohort and differences are observed though not statistically tested. The small numbers in the survey overall also negate the possibility for statistical validation of the evaluation instrument, but the method and the indicative results provide the basis for further development. The results are intended to indicate the potential usefulness of the evaluation instrument and opportunities for developing engineering capabilities in non-engineering students, providing the basis for further research in this area.

\section{Overall performance}

Grouped into their cohorts, CEGE and BASc, the distribution of the total score attained by the students in the 14 competency indicators was collated. Half of all BASc students attained a total score in the low 30 s out of 50 , equivalent to a means score of 3 out of 5 for each item, on the assessment at the beginning of the term. The other half are equally distributed across classifications. In comparison, the CEGE cohort's total scores were more equally spread between 10 and 45 points out of 50 without a peak at 30-35 points. The skew of the distribution of scores was also lower than that of the BASc students. Overall, the cohorts' total score distribution is roughly similar based on the assessment of their performance in the problem-solving exercises at the beginning of the term. 
[Figure 1 here]

At the end of the term the picture looks very different. The BASc cohort's lower scores have shifted to the higher total score bands of 40-45 and 45-50. Most of the BASc students scored more than 35 points in total. This equates the overwhelming majority scoring a mean of 2.5 points on each criteria. The mean total score for the BASc students on the assessment at the end of the term is 41.9 points. By comparison, the CEGE student's mean total score in the end of term assessment was 19.3 points. As Error! Reference source not found. illustrates the CEGE total scores have shifted to the lower end of the axis. A number of students scored less than 5 points in total. This reflects the students scoring zero points in at least 3 out of 4 criteria. Over half of the CEGE cohort scored less than 20 points which equates to a mean score on each of the criteria of less than 1.5.

[Figure 2 here]

The difference in the mean average total score between the two cohorts at the end of the term is striking. CEGE students showed a decline in overall average score, from 25 points to 19 points. The BASc students' average score increased from 31 to 42 points. One of the reasons for this difference could be the different education the two cohorts received over the course of the term, which would have prepared them to tackle problem based learning with a different approach. 


\section{Performance against individual criteria}

Table 3 shows the average results of each evaluation criteria for the two cohorts at the start of term. The scores are out of a possible 5.

[Table 3 here]

Both cohorts performed badly in criteria P 10.4 and B 12.1 which refer to 'hazard awareness' and 'questioning assumptions and information' respectively. In addition, the CEGE students also scored under 1.5 on average in P 7.1 'systematic assessment of information needs'. The CEGE students also did not score well on the criteria referring to 'context awareness', in particular C 2.3 'identifying stakeholders' and C 4.4 'context awareness with reference to politics, social aspects and finance'.

By the end of the term the BASc students have improved on their weak scores in criteria P 10.4 and B 12.1. However, the CEGE student's performance has slipped below a mean score of 1.5 in a few other criteria, as shown in Table 4.

[Table 4 here]

The BASc students on average performed better than the CEGE in all criteria at both the beginning and the end of the term except P 2.2 'attention to detail', P2.6 'identifies and evaluates alternatives' and B 11.2 'original thought and flexible mind' at the beginning of the term. Notably the BASc students outperform the CEGE students on average in all criteria by the end of the term. At the end of the term there is also a 
greater gap between the BASc average performance against the criteria versus the CEGE performance.

Figure 3 illustrates the change between the mean score attained in the assessment at the beginning of the term and at the end of term. Positive scores indicate an improvement in the score attained at the end of the term versus the beginning of the term. A negative score indicates that the attainment levels have dropped at the end of the term versus the beginning of the term. The BASc cohort on average improved their scores by 1 point in all criteria except C 4.4 'context awareness', which dropped by half a point on average. C4.4 'Context awareness', was also exceptional for the CEGE cohort, but with opposite implications. Except for C4.4 which showed no change, the CEGE mean score was lower at the end of the term assessment than at the beginning of the term assessment. The largest drop was in B11.2 which refers to 'original thought and open mindedness'.

[Figure 3 here]

\section{Self-evaluation}

In addition to the tasks in terms of engineering competences, the students were asked to evaluate their own experience of undertaking the problem-solving exercise. This addressed preparedness, anxiety and satisfaction with the task. Students were also asked to describe the elements of their response they were least satisfied with, which elements they would expand if they had more time and which part of their work they had most confidence in. 
[Figure 4 here]

Both cohorts started the term feeling confident with the answer they gave. At the beginning of the term the CEGE students and BASc students rated their capabilities equally highly. By the end of the term, BASc students felt their educational and professional background had equipped them to a higher degree when facing the exercise than at the beginning of the term. This indicated that the courses they took during the term improved their confidence to do this task. By comparison the CEGE cohort felt they were equally well/badly equipped to tackle the task. Both cohorts noted feeling more anxious about the task towards the end of the term. The BASc students' anxiety grew more than that of the CEGE students. However, the CEGE students were more anxious about the task both at the beginning and the end. CEGE students were also less satisfied with the answer they had given at the end of the term compared with the beginning of the term, while BASc students were more satisfied at the end of term than at the beginning.

At the beginning of term CEGE students wrote that their work suffered from lack of technical knowledge and details. Also, they felt the weakest parts were the consideration of context of the plan and feasibility. Like the CEGE students, more than $40 \%$ of BASc students listed the lack of technical detail as their work's greatest weakness. Other concerns raised were implementation, stakeholders, feasibility and project management. By the end of term, both cohort's response fell into two categories: technical knowledge and detail, and implementation. 
At the beginning of term there was a wide range on answers to the question of what the students would explore or expand on if given more time. More than $80 \%$ of CEGE students and nearly $70 \%$ of BASc mentioned they would focus on more detail technical detail. The most popular subsequent answers were the context of the proposal, stakeholders and systems thinking. At the end of the term, the spread of answers was similar but notably fewer topics of further development were mentioned. More technical detail was still the most frequently given answer but in comparison to the beginning of term, only just under $60 \%$ and just over $50 \%$ of BASc and CEGE students respectively, submitted this as an area for improvement in their proposal. There was little difference in the spread and frequency of answers given between the two cohorts. After Technical details, the most popular answers were options and alternatives, stakeholders, context and systems thinking.

Despite technical detail being the most frequently submitted answer to what the weakest element of their work was as well as the area that would needed improvement, nearly $85 \%$ of CEGE students listed the technical and theoretical aspects of their coursework as the element of the work they have the most confidence in. By contrast, the BASc students' answers fell predominately into the categories: context, problem framing. At the end of the term, the CEGE students were no longer as confident in their technical and theoretical abilities. Over $50 \%$ of the CEGE students listed theory and technical aspects as the element of their work they had the most confidence in, nearly the same amount listed the development of options and alternatives as their strongest element. Similarly, to the beginning of the term, the BASc students' answers were more distributed. Stakeholders was the most frequently mentioned answers with close to $40 \%$ of BASc listing stakeholders as the element of their work they had the most confidence 
in. Equally frequent answers fall into the following four categories: technical/theory, context, problem framing/requirements and project management.

\section{Discussion and conclusions}

This study presents results of an evaluation of a new approach to teaching engineering competencies to undergraduate students and a novel evaluation tool using problemsolving exercises integrated with professionally defined engineering competencies. The scope of the study is constrained by the small cohort and the short time-frame of the study. As such, it is intended to report a potential innovation in evaluation of the impact of teaching methods on professional engineering competences, which requires further validation through application and analysis of larger cohorts in different contexts.

The evaluation method was able to show changes within and between cohorts after completing a course of study, though the analysis did not include statistical validation of the instrument. The students on the liberal arts Engineering Thinking module showed overall improvement in professional engineering competences while students on civil and environmental engineering undergraduate programmes show a slight decline over the first term of their studies. On average, liberal arts students scored slightly higher on most competences at the beginning of term than the engineering students. The difference between the cohorts increased by the end of the term, with liberal arts student scoring notably higher on all competencies. These results indicate that the evaluation method is able to show the effect of the teaching intervention, justifying further statistical testing and development of the instrument.

The improvement in professional competencies of the liberal arts students may be attributed to the Engineering Thinking module, as this is the specific aim of the 
course. It may also be influenced by other modules they were taking at the same time in the BASc programme. Given that entry requirements for both courses are of a similarly high standard, this is unlikely to be due to higher initial academic capability of the BASc students. Overall, this indicates that professional competencies can be improved through problem-based learning without requirements to learn conventional engineering science content. Students are able to learn how to 'think like an engineer' without being exposed in detail to the engineering sciences. It also indicates that potential for liberal arts based education to develop professional competencies associated with engineering.

The slight decline in the performance of the engineering students is more difficult to explain. Engineering students felt more anxious and less satisfied with their work at the end of term than at the beginning. This may be because the engineering curriculum did not include specific 'engineering thinking' learning outcomes for the first term of the first year, and that students are becoming more aware of the technical complexities of engineering knowledge, thus undermining their confidence in their abilities. The Engineering Thinking module specifically aimed to develop transferrable engineering skills in students in just one term, while the engineering degrees develop such competences alongside technical competences over the three or four years of the undergraduate engineering programme.

The scenario-based curriculum for the engineering students, though based on principles of problem-based learning, was significantly different to the full project lifecycle approach taken in Engineering Thinking. The more hands-on approach in Engineering Thinking would be more complex and resource intensive to deliver to the full engineering cohort of around 100 students. This demonstrates the challenges of 
achieving the desired outcomes for problem-based learning in large cohorts, and shows the diversity of approaches and outcomes within the problem-based approach.

The ultimate purpose of the study was to determine whether it is possible for liberal arts students to develop engineering competencies, without detailed engagement with the engineering sciences. The results of the evaluation indicate that problem-based learning supported by interdisciplinary seminars, readings and other learning exercises, can improve student competence in attributes associated with professional engineering.

References:

Bell, S., P. Galilea, and R. Tolouei. 2010. "Student experience of a scenario-centred curriculum.” European Journal of Engineering Education 35 (3): 235-245.

Blake, R. and O. Gutierrez. 2011. "A semantic analysis approach for assessing professionalism using free-form text entered online." Computers in Human Behaviour 27: 2249-2262.

Briedis, D. 2002. "Designing effective assessment of student professional outcomes." International Journal of Engineering Education 18 (2): 208-216.

Brumm, T., L. Hanneman and S. Mickelson. 2006. “Assessing and developing program outcomes through workplace competencies." International Journal of Engineering Education 22 (1): 123-129.

Burrow, M., H. Evdorides, B. Hallam and R. Free-hewish. 2005. "Developing formative assessments for postgraduate students in engineering." European Journal of Engineering Education 30 (2): 255-263.

Denayer, I., K. Thaels, J. Vander Sloten and R. Gobin. 2003. "Teaching a structured approach to the design process for undergraduate engineering students by problem-based education.” European Journal of Engineering Education 28 (2): 203-214.

Fernandes, J. M., N. van Hattum-Janssen, A. Nestor Ribeiro, V. Fonte, L. Paulo Santos and P. Sousa. 2012. "An integrated approach to develop professional and 
technical skills for informatics engineering students." European Journal of Engineering Education 37 (2): 167-177.

Gavin, K. 2001. "Case study of a project-based learning course in civil engineering design.” European Journal of Engineering Education 36 (3): 547-558.

Graham, R. and E. Crawley. 2010. "Making projects work: a review of transferable best practice approaches to engineering project-based learning in the UK." Engineering Education: 5 (2), 41-49.

Imrie, B. W. 1995. "Assessment for learning: quality and taxonomies.” Assessment and Evaluation in Higher Education 20 (2): 175-189.

Institution of Civil Engineers. 2011. Competency Framework for Professional Development. London.

Jaeger, M. and D. Adair. 2014. "Two consecutive project-based engineering design courses - an analysis of portfolio assessment results." Interdisciplinary Engineering Design Education Conference, Santa Clara, California.

Male, S., M. Bush and E. Chapman. 2010. "Understanding generic engineering competencies.” Proceedings of the 2010 AaeE Conference, Sydney.

McMartin, F., A. McKenna and K. Youssefi. 2000. "Scenario assignments as assessment tools for engineering education.” IEEE Transactions on Education 43 (2): 111-119.

Mills, J. and D. Treagust. 2003. "Is problem-based or project-based learning the answer?" Australasian Journal of Engineering Education 3: 2-16.

Palmer, S. and W. Hall. 2011, "An evaluation of a project-based learning initiative in engineering education.” European Journal of Engineering Education 36 (4): 357365.

Segalàs, J., D. Ferrer-Balas and K. Mulder. 2008. “Conceptual maps: measuring learning processes of engineering students concerning sustainable development.” European Journal of Engineering 33 (3): 297-306.

Shuman, L.J., M. Besterfield-Sacre and J. McGourty. 2005. "The ABET "Professional Skills" - Can they be taught? Can they be assessed?" Journal of Engineering Education 94 (1) 41-55. 
Table 1 Competency Indicators from the Institution of Civil Engineer's Competency

Framework for Professional Development taken to assess student performance in problem-solving exercises. Indicators are categorised as Practice (P), Behavioural (B) and Contextual $(\mathrm{C})$ competencies.

P 2 Problem Solving - The effective application of engineering knowledge to arrive at an appropriate solution(s)

P 2.1 Contributes to the identification of problems and the production of practical solutions

P 2.2 Demonstrates the appropriate amount of attention to detail

P 2.3 Logically assesses situations to identify constrains, root causes, patterns, interrelationships, implications and potential benefits

P 2.5 Capable of complex analysis through critical thinking

P 2.6 Identifies and evaluates alternative solutions

P 4 Organisation and Planning - The ability to translate requirements into action

P 4.1 Identifies and arranges tasks systematically to meet requirements

P 6 Technology Management - Displays a proactive and responsible attitude toward the use of existing and emerging technology

P 6.5 Actively seeks information/advice concerning the latest applicable technology

P 7 Information and Knowledge Management - The location, collection, review and validation, summarising, storing and dissemination of information

P 7.1 Systematically identifies information needs and addresses them.

P $10 \quad$ Health \& Safety - Effectively applies and promotes a responsible attitude towards health, safety and wellbeing

P 10.4 Is hazard aware-Recognises potential risks to health, safety and wellbeing and acknowledges high-risk activities. .

B 11 Creativity - Work and acts in an original manner for the formation of imaginative or novel solutions

B 11.2 Remains flexible and open to original thoughts. .

B 12 Information Seeking - A strong desire for exhausting all sources of useful information about a situation, environment or problem.

B 12.1 Proactively questions assumptions and sources of information. .

C 2 Organisational Awareness -Displays an understanding of the business environment in which you operate.

C 2.3 Is able to identify relevant internal and external stakeholders/partners.

C 4 Commercial Market Awareness -Uses an awareness of the external organisational context to search for opportunities.

C 4.4 Aware of political, economic, technological, legal, environmental and situational drivers and trend that may affect current or future work and opportunities.

C 6 Sustainable and Resilient Approach -Considers the short and long tern impact and maintenance of actions and recommendations. 
C6.2 Appreciates the effect decisions may have on the environment and community and selects solutions with a reasonable level of impact.. 
Table 2 Institution of Civil Engineers' Competency Framework for Professional Development (ICE, 2011)

\begin{tabular}{|l|l|}
\hline Range & Description \\
\hline 1 & $\begin{array}{l}\text { None } \\
\text { Competency not demonstrated, or only basic awareness. Needs } \\
\text { supervision/assistance }\end{array}$ \\
\hline 2 & $\begin{array}{l}\text { Low } \\
\text { Low but progressing awareness and demonstration. Would benefit from } \\
\text { mentorship or greater experience }\end{array}$ \\
\hline 3 & $\begin{array}{l}\text { Good } \\
\text { Good awareness and demonstration of competency. Regularly demonstrates } \\
\text { many of the indicators, may need to focus on specific attributes }\end{array}$ \\
\hline 4 & $\begin{array}{l}\text { Informed } \\
\text { Sound awareness, understanding and demonstration of competency. }\end{array}$ \\
\hline 5 & $\begin{array}{l}\text { Model } \\
\text { Exemplary demonstration of competency }\end{array}$ \\
\hline
\end{tabular}


Table 3 Mean score out of 5 attained by cohort in assessment at the beginning of the year. Indicators are categorised as Practice (P), Behavioural (B) and Contextual (C) competencies.

\begin{tabular}{|l|l|l|}
\hline & Mean BASc & Mean CEGE \\
\hline P 2.1 Identifies problems \& finds practical solutions & 2.8 & 2.6 \\
\hline P 2.2 Attention to detail & 2.2 & 2.2 \\
\hline P 2.3 Logical assessment of complexity of problem & 2.6 & 2.1 \\
\hline P 2.5 Critical thinking & 2.5 & 1.9 \\
\hline P 2.6 Identifies and evaluates alternatives & 2.3 & 2.5 \\
\hline P 4.1 Systematic approach to tasks & & 2.9 \\
\hline P 6.5 Seeks latest on applicable technology & 2.6 & 1.9 \\
\hline P 7.1 Systematic assessment information needs & 2.0 & 1.3 \\
\hline P 10.4 Hazard aware & 1.4 & 0.8 \\
\hline B 11.2 Original thought and flexible mind & 2.4 & 2.4 \\
\hline B 12.1 Questions assumption \& information & 1.3 & 0.8 \\
\hline C 2.3 Identifies stakeholders & 2.1 & 1.2 \\
\hline C 4.4 Context aware & 2.3 & 1.0 \\
\hline C 6.2 Impact aware & 2.1 & \\
\hline
\end{tabular}


Table 4 Mean score out of 5 attained by cohort in assessment at the end of the year. Indicators are categorised as Practice (P), Behavioural (B) and Contextual (C) competencies.

\begin{tabular}{|l|l|l|}
\hline & BASc & CEGE \\
\hline P 2.1 Identifies problems \& finds practical solutions & 3.4 & 2.2 \\
\hline P 2.2 Attention to detail & 3.5 & 1.9 \\
\hline P 2.3 Logical assessment of complexity of problem & 3.6 & 1.5 \\
\hline P 2.5 Critical thinking & 3.5 & 1.6 \\
\hline P 2.6 Identifies and evaluates alternatives & 3.1 & 1.9 \\
\hline P 4.1 Systematic approach to tasks & 4.0 & 1.9 \\
\hline P 6.5 Seeks latest on applicable technology & 2.8 & 1.3 \\
\hline P 7.1 Systematic assessment information needs & 3.3 & 1.1 \\
\hline P 10.4 Hazard aware & 1.9 & 0.4 \\
\hline B 11.2 Original thought and flexible mind & 2.9 & 1.5 \\
\hline B 12.1 Questions assumption \& information & 2.3 & 0.6 \\
\hline C 2.3 Identifies stakeholders & 2.7 & 0.7 \\
\hline C 4.4 Context aware & 1.9 & 1.0 \\
\hline C 6.2 Impact aware & 3.1 & 1.7 \\
\hline
\end{tabular}


Figure 1



Figure 2

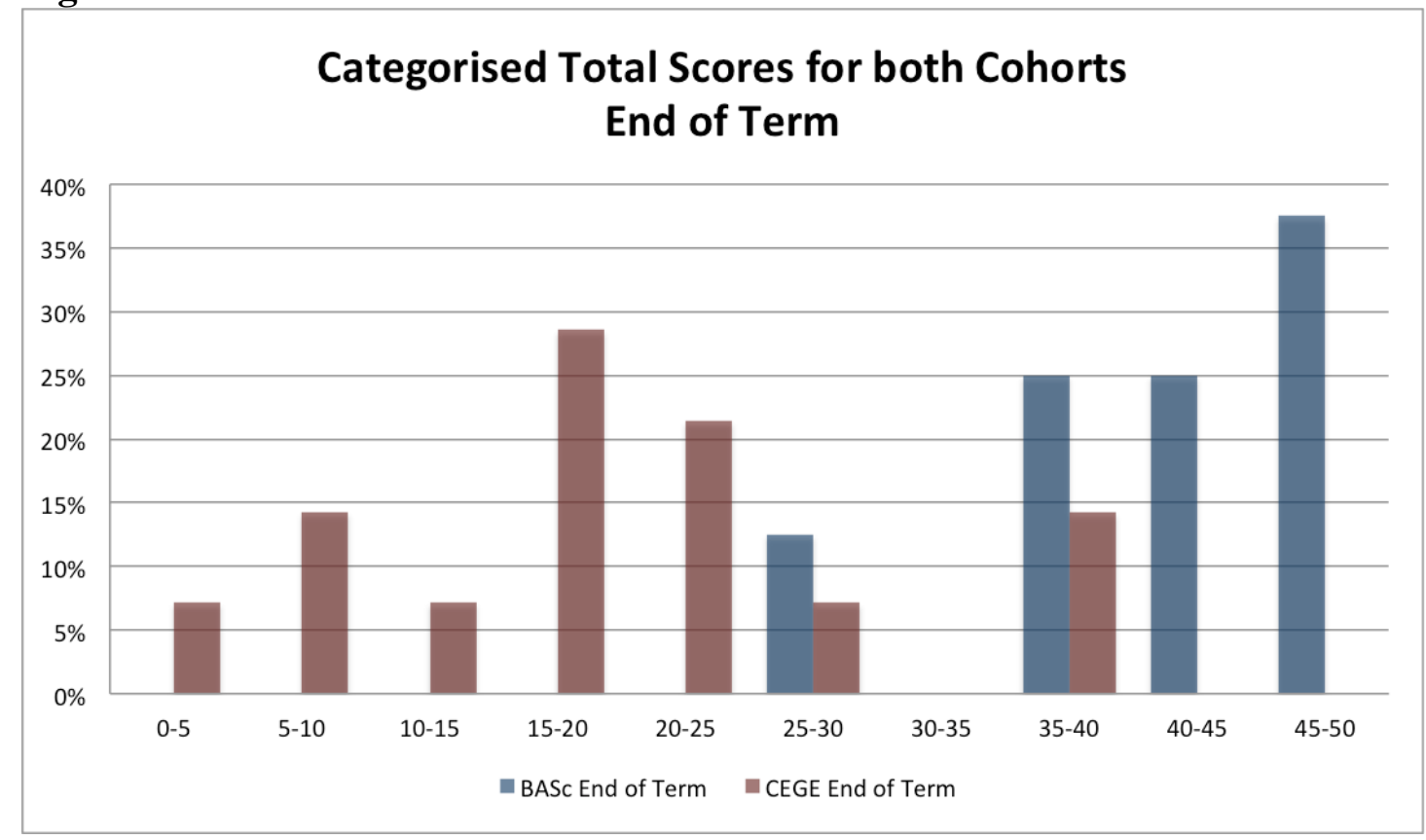


Figure 3

Point Change between Mean Average Performance of Cohort on Scenario Beginning vs End of Term

(i.e. End of Term Score - Beginning of Term Score)

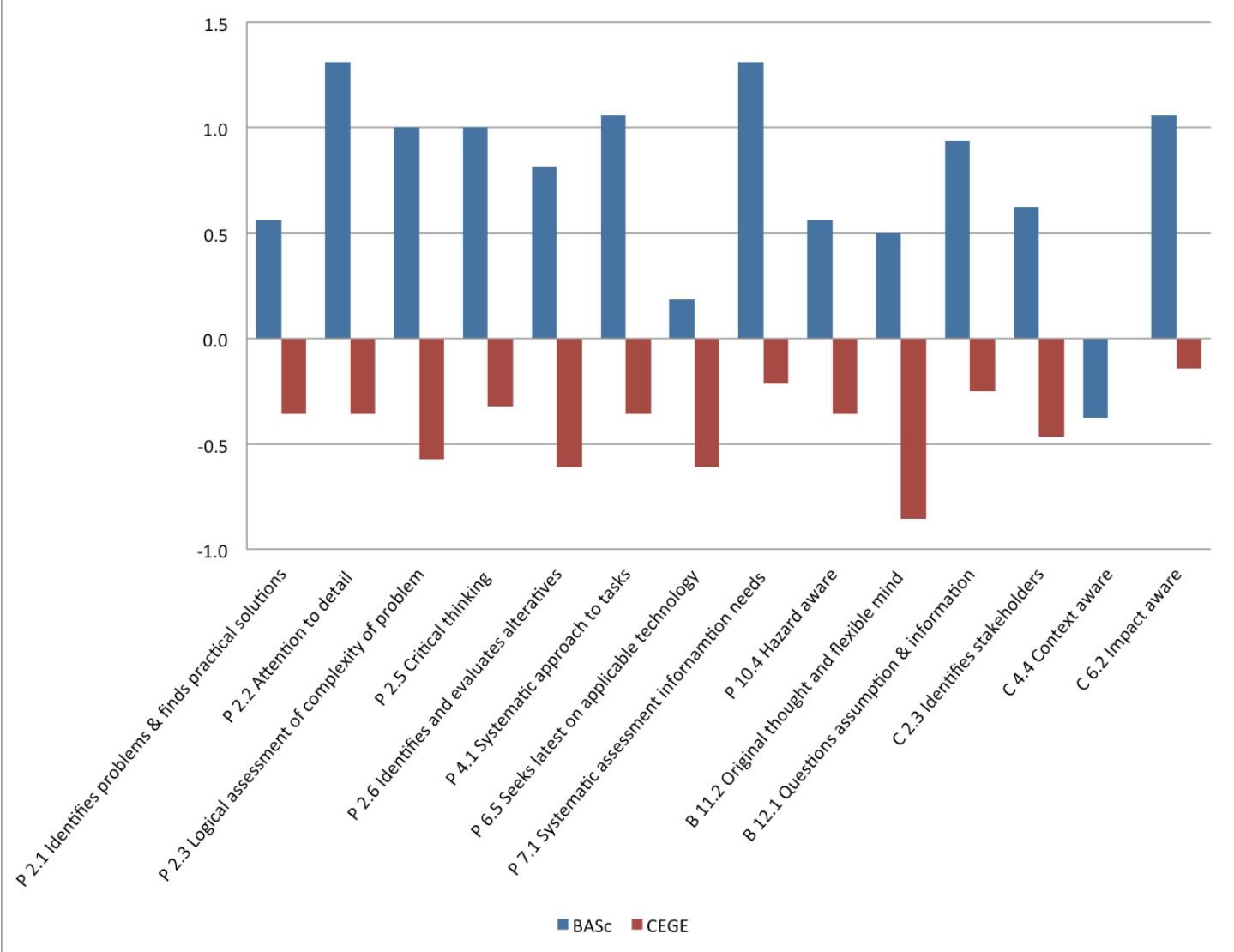


Figure 4

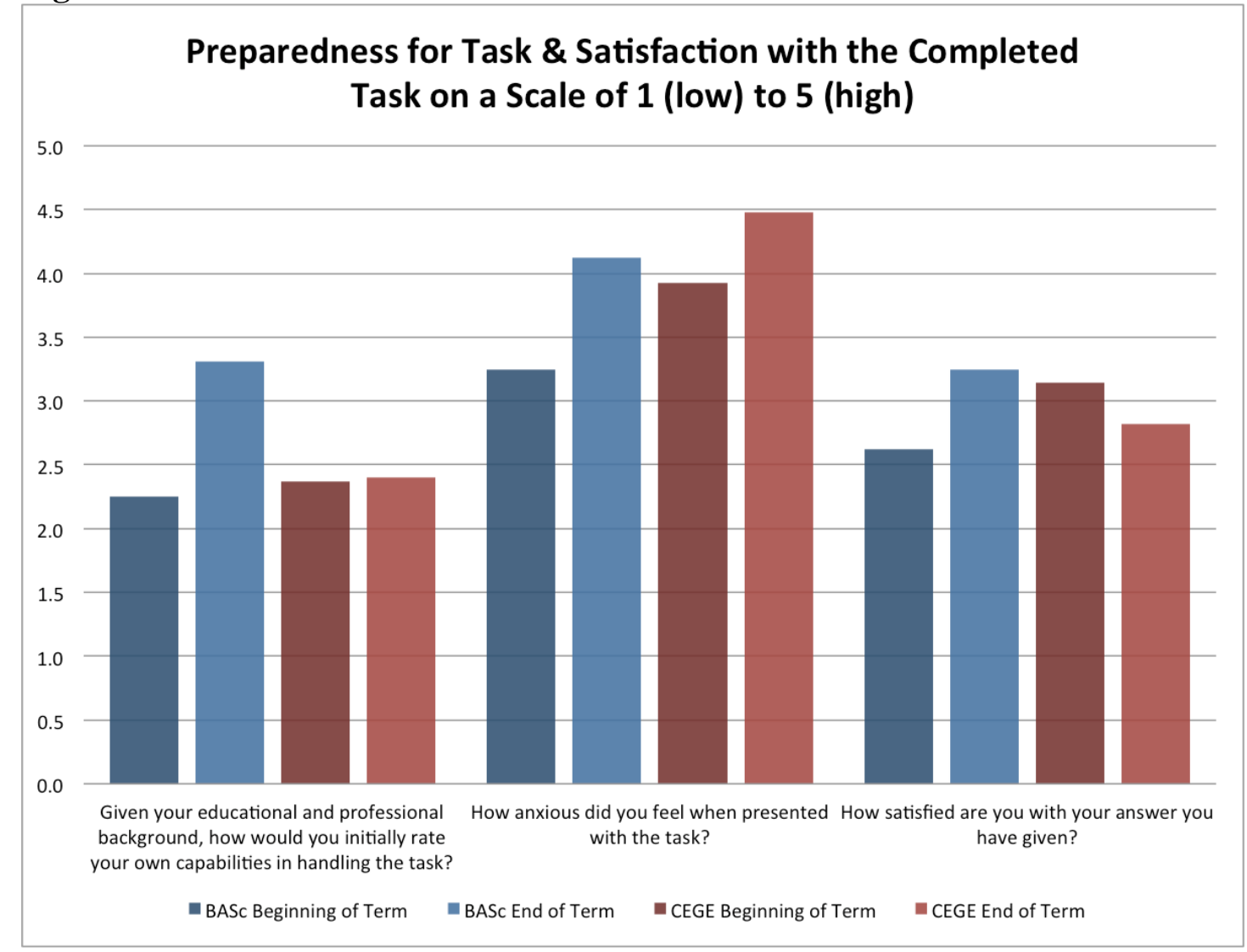


Figure 1 Scores of BASc and CEGE students at the Beginning of the Term categorised in five point bands.

Figure 2 Scores of BASc and CEGE students at the End of the Term categorised in five point bands.

Figure 3 Point change mean average of cohort between the beginning and end of term assessment. Indicators are categorised as Practice (P), Behavioural (B) and Contextual (C) competencies.

Figure 4 Student self-evaluation of preparedness for the task. 